\title{
The role of middens in white rhino olfactory communication
}

Courtney Marneweck ${ }^{\mathrm{a}^{*}}$, Andreas Jürgens ${ }^{\mathrm{b}}$, Adrian M Shrader ${ }^{\mathrm{ac}}$

${ }^{a}$ School of Life Sciences, University of KwaZulu-Natal, South Africa.

${ }^{b}$ Chemical Plant Ecology, Technische Universität Darmstadt, Germany.

${ }^{c}$ Mammal Research Institute, Department of Zoology and Entomology, University of

Pretoria, South Africa.

*Corresponding author: Courtney Marneweck, School of Biology and Environmental

Sciences, University of Mpumalanga, South Africa, courtney.marneweck@gmail.com, $+27726025673$.

\begin{abstract}
White rhinos (Ceratotherium simum) use dung odours to transmit information about their sex, age, territorial status (males) and oestrous state. Moreover, as white rhinos defecate in communal middens (i.e. dung heaps, or latrines) it has been suggested that these middens may act as information centres. However, it is uncertain which individuals primarily transmit information via middens, or for whom this information is intended. Using video-recording camera traps, we investigated the behaviour of white rhinos at middens. We hypothesised that territorial adult males would visit, defecate, and sniff other dung more than other adults. In line with this, we found that they visited and defecated more than other individuals. Moreover, territorial males and potential male challengers were the main individuals to investigate dung piles. These olfactory investigations focused primarily on territorial male and adult female dung (male-male and female-male communication). Adult females and subordinate males also investigated territorial male and female dung as much as other males did, suggesting male-female and female-female communication. In addition to olfactory signals, there was a spatial aspect to midden use, where territorial males defecated only in the centre of a midden, while other individuals defecated primarily around the periphery. Yet, subordinate males also tended to defecate in the centre, suggesting an indication of residency. Lastly, territorial males defecated more
\end{abstract}


frequently than any other adult, and were able to do so by regulating their dung output (i.e. producing smaller volumes). Our results indicate that middens act as information centres, where the primary function seems to be for territorial males to transmit and obtain information. However, non-territorial males may also assess female reproductive state, while females may be assessing the quality of all males, and the number of other females using a midden. Ultimately, our results highlight the importance of middens in white rhino communication.

\section{Keywords}

Communal defecation, dung piles, inter-sexual communication, intra-sexual communication, olfaction

\section{Introduction}

Many mammals use olfactory cues to communicate information including kin recognition (Stoffel et al., 2015), reproductive status (Archunan \& Rajagopal, 2013), and territory ownership (Barja, de Miguel, \& Bárcena, 2005). This information can be transmitted via scent glands (Cross, Zedrosser, Nevin, \& Rosell, 2014; Vaglio et al., 2016), urine (Archunan \& Rajagopal, 2013; Kimura, 2001), and/or dung (Karthikeyan, Muniasamy, SankarGanesh, Achiraman, \& Archunan, 2013; Marneweck, Jürgens, \& Shrader, 2017a). As many mammals defecate in communal middens (i.e. dung heaps, or latrines), it has been suggested that these middens may act as information centres (Eppley, Ganzhorn, \& Donati, 2016; Rodgers, Giacalone, Heske, Pawlikowski, \& Schooley, 2015). Middens can be found in the centre of a territory or home range (e.g. swift fox Vulpes velox (Darden, Steffensen, \& Dabelsteen, 2008)), or along the boundary (e.g. oribi Ourebia ourebi (Brachares \& Arcese, 1999)). Further, the location of a midden has implications for its function. For instance, middens at the edge of a territory are likely used more for territorial marking, whereas middens in the centre may be used for social group communication (Dröscher \& Kappeler, 2014; Jordan, Cherry, \& Manser, 2007).

Middens of several ungulate species are utilised by both sexes, for example, dik-diks Madoqua kirkii (Hendrichs \& Hendrichs, 1971), klipspringers Oreotragus oreotragus (Dunbar \& Dunbar, 1974), bushbucks Tragelaphus scriptus (Wronski, Apio, \& Plath, 2006), and Arabian gazelles Gazella arabica (Wronski, Apio, Plath, \& Ziege, 2013). Although these species utilise 
middens, their mating strategies differ. Specifically, dik-diks and klipspringers are facultatively monogamous (Brotherton \& Manser, 1997; Roberts \& Dunbar, 2000), whereas bushbucks and Arabian gazelles are polygynous (Wronski, 2005; Wronski et al., 2013). However, even though species share a mating strategy, how they utilise middens can differ. For example, polygynous bushbucks use middens for inter-sexual communication (i.e. male-female communication) (Wronski et al., 2006), while polygynous Arabian gazelle middens have a dual function of both male territorial defence (i.e. male-male communication) and within-female group communication (i.e. female-female communication) (Wronski et al., 2013).

White rhinos (Ceratotherium simum) employ a polygynous mating strategy where adult males defend a territory and monopolise mating opportunities with multiple females (White, Swaisgood, \& Czekala, 2007). They do this by defending small territories (average $1.65 \mathrm{~km}^{2}$ ) that are part of larger, overlapping, female home ranges (average $11.6 \mathrm{~km}^{2}$ ) (Owen-Smith, 1973, 1975). Thus, one female home range incorporates a number of male territories. Within their territories, white rhino males can have >30 middens (Owen-Smith 1973) distributed across the landscape (Kretzschmar, Ganslosser, Goldschmid, \& Aberham, 2001). However, these middens tend to be concentrated around frequented paths, water holes, and territory boundaries (Owen-Smith, 1975), as in black rhinos (Schenkel \& Schenkel-Hulliger, 1969), and Indian rhinos (Laurie, 1982). Their placement tends to suggest that a key function of middens is territorial marking, and thus they are likely primarily utilised by territorial males. However, individuals of both sexes of white rhinos defecate in middens (Owen-Smith, 1973). Moreover, as white rhinos transmit information about their sex, age, male territorial status, and female oestrous state in the odour of their dung (Marneweck et al., 2017a), it is likely that these middens act as information centres. It is unclear, however, if these middens are utilised equally by the different sex and age classes (e.g. males, females, territorial males, subordinate males), or whether the information is only utilised by specific individuals (e.g. territorial males).

The key information transmitted by white rhinos in their dung odours (i.e. territory ownership and oestrous state (Marneweck et al., 2017a)) is related to breeding opportunities. Therefore, it is likely that adults are the key utilisers of middens. Territorial males should use middens to both advertise territory ownership and search for mates (Brachares \& Arcese, 1999; Wronski et al., 2006). 
Although it was originally thought that territorial male white rhinos monopolised mating, sneaky copulations by nonterritorial males can occur (Guerier, Bishop, Crawford, Schmidt-Kuntzel, \& Stratford, 2012), suggesting that these males could also use middens as a way to search for mates. Nonterritorial males can be divided into two categories, those living within a territory but not challenging the territorial male for ownership (i.e. subordinate), and those that are passing through a territory gathering information with the potential of challenging a territorial male for territory ownership (Dunham, Warner, \& Lawson, 1995; Owen-Smith, 1973). Based on their different priorities, these nonterritorial males will likely behave differently at middens. For example, subordinate males may investigate female dung looking for sneaky mating opportunities, whereas visiting males may investigate the territorial male's dung to assess his condition. In addition to males, females likely also obtain information as well as deposit it within middens. Contrastingly, females do not maintain exclusive home ranges (Rachlow, Kie, \& Berger, 1999), or compete for mates with other females (Owen-Smith, 1973). However, they may use middens to assess male quality, especially if mating occurs outside of territory ownership.

Despite the appearance of white rhino middens simply being a collection of dung, there seems to be some degree of order with regard to the placement of dung within these middens (Owen-Smith, 1973). Specifically, Owen-Smith (1973) suggested that territorial males tended to defecate in the centre of middens, while adult females and sub-adults defecated around the periphery. As white rhino middens are large (up to $30 \mathrm{~m}$ diameter; average diameter at largest length $7 \pm 0.29 \mathrm{~m}, N=149$; Marneweck et al. unpublished data), spatial distribution is possible. If this is the case, then there is not only an olfactory component to dung, but also a spatial component of dung placement within middens that further facilitates information transfer. At a larger spatial scale, there can be $\geq 30$ middens within a male's territory, and these males defecate in a number of these middens daily (Owen-Smith, 1973). As dung is a limited resource, the question that then arises is, how do they do this? It may be possible that to maximise the distribution of dung, males regulate their dung output, relative to nonterritorial males and adult females. This behaviour has been reported for male oribi antelope (Brachares \& Arcese, 1999). If so, then by limiting dung output per defecation, territorial male white rhinos would then be able to increase the number of marking events, and thus mark a greater total area. With the 
above points in mind, we hypothesised that; (1) territorial males would visit and defecate in middens more frequently than other adults (i.e. nonterritorial male or adult female), (2) as territorial males obtain a majority of the breeding opportunities, they should spend more time investigating (i.e. sniffing) dung within middens compared to other adults (i.e. nonterritorial male or female), and focus this investigation on the dung from adult females, (3) despite their larger body size (2300 kg vs 1600 $\mathrm{kg}$ of adult females; Owen-Smith (1988)) and thus greater potential dung output, territorial males would regulate their dung output, relative to nonterritorial males and adult females, to increase marking events, and (4) only territorial males would defecate in the centre of the middens.

\section{Methods}

\section{Behavioural data collection}

We conducted this study in the $896 \mathrm{~km}^{2}$ Hluhluwe-iMfolozi Park (HiP), KwaZulu-Natal, South Africa (-28.219853 S, 31.951865 E), from November 2014 to August 2015. This resulted in approximately five months of wet season data (November 2014 - March 2015) and five months of dry season data (April 2015 - August 2015) for each midden. The average territory size of a white rhino in HiP is 1.65 $\mathrm{km}^{2}$ (Owen-Smith, 1975). Therefore, to help ensure separation, we selected focal middens that were separated by at least $2 \mathrm{~km}$. Video footage of the territorial males utilising these middens indicated that the middens were in fact in separate territories (see below). To record midden visits and use, we set up motion-triggered video recording camera traps at ten middens, each with a different resident territorial male (identified via differences in horn shape and size). We used infrared camera traps (either a Cuddeback Black Flash ${ }^{\circledR}$ E3 or Cuddeback Attack Black Flash ${ }^{\circledR} 1194$ model) placed approximately 3 metres from the edge of the midden to allow for sufficient field of view. These cameras do not emit visible light or have a flash, creating minimal disturbance at the midden and therefore allowing us to capture natural behaviour. We programmed the cameras to record 30 -second videos at each trigger with a 1-second delay before becoming active again. 


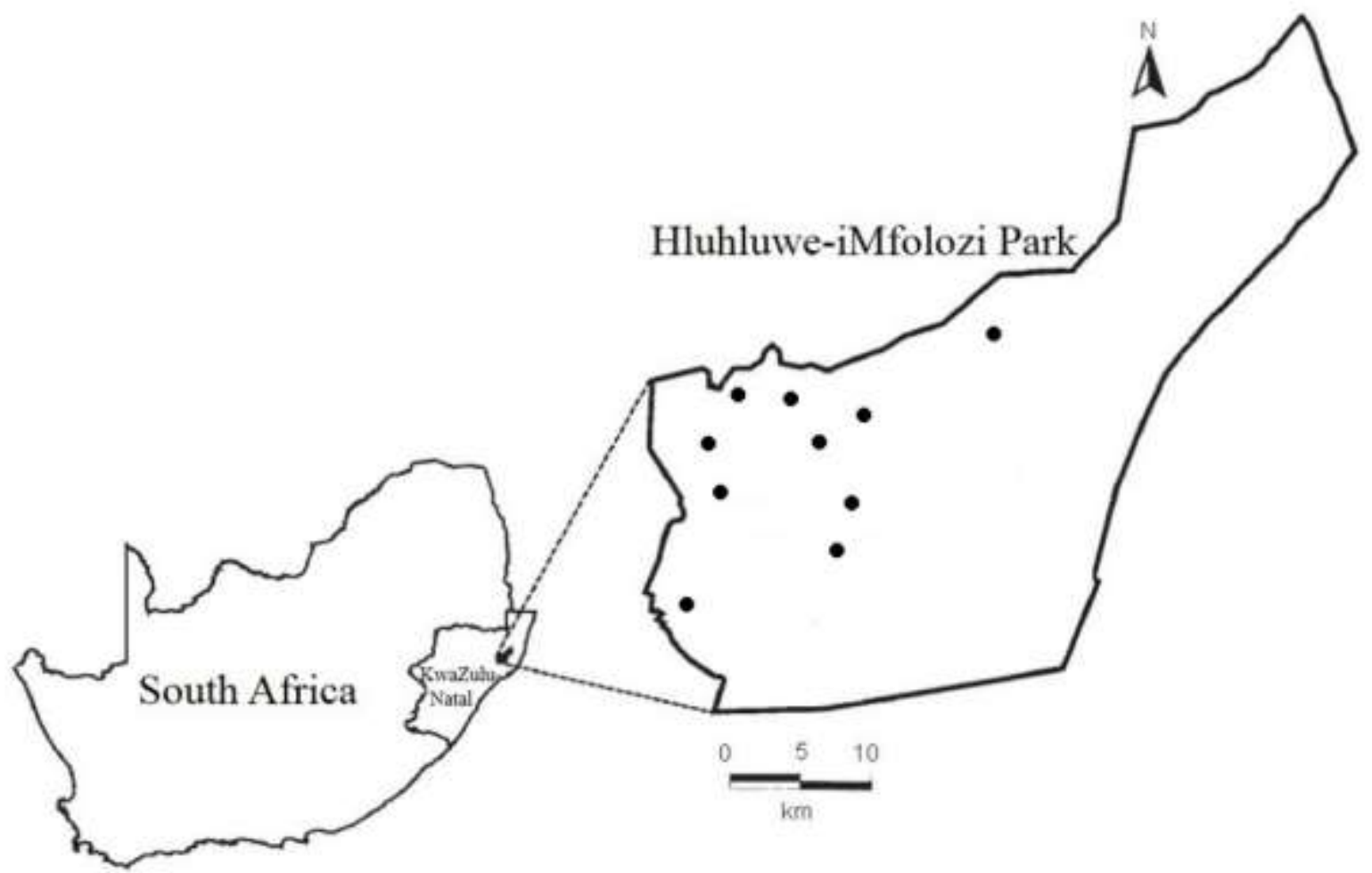

Figure 1. Location of Hluhluwe-iMfolozi Park, KwaZulu-Natal, South Africa. Dots represent focal midden sites $(N=10)$.

We recorded data on all the individuals that visited the middens. From 2403 data videos, we created an ID profile for each white rhino ( $N=233$ individuals), so that we could record individual visits, defecation, and olfactory investigation. When individuals sniffed specific dung piles, we determined the age and sex of the white rhino that deposited the dung by reviewing previous video footage. Adults were identified as individuals $>7$ years, sub-adults as 2-7 years, and calves $<2$ years, based on body size and horn development (Hillman-Smith, Owen-Smith, Anderson, Hall-Martin, \& Selaladi, 1986). Territorial males were identified as adult males performing territorial behaviours (i.e. dung kicking, spray urinating) at the middens, and nonterritorial as adult males not performing these behaviours (Owen-Smith, 1971, 1973; Pienaar, Bothma, \& Theron, 1993; Rachlow et al., 1999).

Living within a white rhino territory, there tends to be one or two subordinate adult males whom the territorial males tolerates (Owen-Smith, 1973). These males do not help defend the territory, nor do they try and challenge the territorial male for territory ownership (Owen-Smith, 1973). Challenges for territory ownership tend to come from lone adult males entering the territory 
(Dunham et al., 1995; Owen-Smith, 1973). Yet, these visits are infrequent (Owen-Smith, 1973, 1975).

To distinguish these two nonterritorial males, we identified subordinate males as lone, nonterritorial adult males that were relatively frequent visitors to the middens (i.e. visiting $>5 \%$ of camera active days) but did not perform territorial behaviours (i.e. dung kicking). Potential challengers were identified as lone, nonterritorial adult males who infrequently visited middens (i.e. $<5 \%$ of camera active days), and occasionally performed territorial behaviours. We generated the $5 \%$ cut off based on the visit data. In our study, we found a clear divide in the midden visits by nonterritorial males, with 'frequently' seen individuals visiting on average $9 \% \pm 1.3 \%$ of the observation period (average 222 days) and infrequent visitors visiting only $1 \pm 0.1 \%$ of the observation period. In contrast, territorial males visited the middens $20 \pm 3.8 \%$ of the observation period.

The oestrous state of adult female white rhinos can be determined by the behaviour of territorial males. Specifically, when a female is in oestrus, a territorial male moves with her and tries to prevent her from leaving his territory (Owen-Smith, 1973; Pienaar et al., 1993). Moreover, the territorial male will attempt to rest his chin on her flank and eventually mount her (Owen-Smith, 1973). Unfortunately, despite observing territorial males following oestrous females (Marneweck pers. obs.), we did not record these sorts of behaviours at the middens with the camera traps. As a result, we could not determine oestrous state, and thus grouped all adult females together for analysis. Statistical analysis

For all linear mixed effects models, we tested that the assumptions of a linear model were met using the diagnostics normal QQ plot, residual-fitted plot, and histogram for model residuals. For all models, we also tested for collinearity between the fixed factors of age and sex, of which there was none (VIF= 1.1). However, as the third fixed factor (state) utilises a subset of the data (adults only), model selection and comparison via AIC values was not possible. Thus, for all following analyses, we created two models; one for age and sex, and a second for state using a subset of the data.

Visit and defecation frequency

We calculated individual visit and defecation frequency by dividing the number of visits or defecations by the number of days the camera was active (range $=172-282$ days). To assess 
differences in midden visit and defection frequency for each age and sex, we ran a linear mixedeffects model using the R package nlme (Pinheiro, Bates, DebRoy, Sarkar, \& Team, 2015). We set visit or defecation frequency as the response variable, age and sex, plus their interaction, as fixed factors, and rhino ID as a random factor. We then repeated this with adult state as the fixed factor (i.e. territorial male, subordinate male, potential challenging male, or female).

Information acquisition

For analysis of information acquisition, we recorded each midden visit $(N=1675)$ with a yes or no regarding olfactory investigation (i.e. acquiring information). We defined olfactory investigation as standing still and sniffing a dung pile (nose $<20 \mathrm{~cm}$ from ground with nostril flares). To investigate which age and sex deposited or acquired information most often during their visits, we ran a generalised linear mixed-effects model with a binomial distribution using the R package lme4 (Bates, Maechler, Bolker, \& Walker, 2015). We set the number of visits containing investigation as the response variable, age and sex, plus their interaction, as fixed factors, and rhino ID as a random factor. As above, we then repeated this with adult state as the fixed factor (i.e. territorial male, subordinate male, potential challenging male, or female).

After each olfactory investigation event, we looked back into the video log to identify the depositor of the dung pile. By doing this, we were able to identify the depositor of 593 of 772 (77\%) of the sniffed dung piles, and thus limited our analysis to these 593 data points. To assess which adult dung piles were investigated by each adult state (i.e. territorial male, subordinate male, potential challenging male, or female), we ran a generalised linear mixed-effects model with a binomial distribution. We set state of the investigator as the response variable, sex of the dung owner as the fixed factor, and rhino ID as a random factor. We then repeated this same analysis but used state of the dung owner as a fixed factor. Further, to assess the difference in the proportion of adult dung piles that were investigated by each adult state, we conducted a chi squared test with post hoc comparisons. Dung weight To compare the weight of the dung pile deposited, we collected 40 whole dung samples from different adult white rhinos (territorial males $N=12$, nonterritorial males $N=10$, oestrous females $N=4$, non- 
oestrous females $N=14$ ) between January and May 2015. We followed individuals on foot (two people; one researcher and one armed guard) until defecation occurred so we were able to record territorial and oestrous state from observed behaviour (Pienaar et al., 1993; Rachlow et al., 1999). However, we were unable to classify nonterritorial males as either subordinate or potential challengers and thus grouped them together for analysis.

Territorial males spread their dung by kicking after defecation (Owen-Smith, 1973). As a result, it is not as easy to collect as the dung deposited by females and nonterritorial males. However, as the dung was fresh ( $<5$ minutes from defecation), the temperature, colour, and moisture of the dung made it easily distinguishable from older dung in the midden. We spread and dried each dung pile in direct sunlight for 72 hours and then weighed the contents to determine dry weight. As data were not normally distributed, we performed a Kruskal-Wallis with post hoc Dunn's test to explore any differences in dry weight.

Defecation location

Finally, from 433 observed defecations, we recorded the location of each dung pile according to each midden's dimensions and categorised them into one of four locations; centre, mid-range, edge, or outside the midden. Middens are often ellipses, and the average diameter of the widest part was $7.7 \mathrm{~m}$ $($ range $=5-10 \mathrm{~m})$ and the narrowest part $5.5 \mathrm{~m}($ range $=3-8 \mathrm{~m})$. The average area of the middens was $34.1 \mathrm{~m}^{2}\left(\right.$ range $\left.=15.7-50.3 \mathrm{~m}^{2}\right)$. They are located on flat ground with the centre indicated by a depression created by the kicking of territorial males while they defecate (Owen-Smith, 1973). We divided each midden into zones of approximate thirds. For small middens $\left(<30 \mathrm{~m}^{2}\right)$, we classified the centre as a $1.5 \mathrm{~m}$ radius from the centre most point, the mid-range as a 1.5-3 m radius from the centre most point, the edge as a 3-4.5 m radius from the centre most point. Anything further than $1 \mathrm{~m}$ from the edge of the midden was considered outside. For medium sized middens (30-40 $\mathrm{m}^{2}$ ), we classified the centre as a $2.5 \mathrm{~m}$ radius around the centre most point, the mid-range as a $2.5-5 \mathrm{~m}$ radius from the centre point, edge as 5-7.5 m from the centre point, and anything over $1 \mathrm{~m}$ from the edge as outside the midden. For large middens $\left(>40 \mathrm{~m}^{2}\right)$, we classified the centre as a $3 \mathrm{~m}$ radius around the centre most point, mid-range as 3-6 $\mathrm{m}$ from the centre point, edge as 6-9 $\mathrm{m}$ from the centre point and, as in the other middens, anything over $1 \mathrm{~m}$ from the edge as outside. 
To assess the effect of age and sex on chosen defecation location, we ran a linear mixed effects model. We set location of defecation as the response variable, age and sex, plus their interaction, as fixed factors, and rhino ID as a random factor. We then repeated this for the fixed factor of adult state. All statistical analyses and figures were created using RStudio version 0.99 .903 for Windows (Team, 2016).

\section{Ethical note}

In order to minimise disturbance, we never approached a midden when a white rhino was present. Further, the cameras we used emitted no visible flash or audio, and we placed them 3 metres from the edge of a midden, attached to a nearby tree. Additionally, we utilised our resources in such a way that batteries and memory cards were changed only once per month to further minimise any potential disturbance at the sites. Cameras were present to record behaviour at the sites, and we conducted no potentially harmful manipulations. We recorded no distress or behavioural manipulation as a result of the camera placement.

Table 1. Total number of individual adults visiting each midden during the study

\begin{tabular}{lccccc}
\hline & \multicolumn{2}{c}{ Number of adult individuals visiting over sample period } & \\
Midden ID & Territorial male & \multicolumn{2}{c}{ Nonterritorial males } & & \\
\cline { 3 - 5 } M0006 & 1 & Subordinate & Potential challenger & Female & Total \\
M0079 & 1 & 1 & 2 & 8 & 12 \\
M0113 & 1 & 2 & 0 & 4 & 6 \\
M0127 & 1 & 1 & 0 & 5 & 8 \\
M0128 & 1 & 0 & 1 & 10 & 13 \\
M0129 & 1 & 0 & 3 & 7 & 11 \\
M0131 & 1 & 1 & 4 & 11 & 16 \\
M0132 & 1 & 2 & 2 & 11 & 15 \\
M0136 & 1 & 3 & 1 & 5 & 9 \\
M0142 & 1 & 2 & 0 & 11 & 15 \\
Total & 10 & 13 & 0 & 7 & 10 \\
\hline
\end{tabular}




\section{Results}

We observed little variation in midden use between sub-adults and calves, thus we only present data associated with adults. All results referring to age can be found in Appendix 1.

\section{Visit and defecation frequency}

State significantly affected the visit frequency of adults, where territorial males visited significantly more often than nonterritorial males and females (Table 2; Fig. 2). Within nonterritorial males, subordinates visited $85 \%$ more often than potential challengers, and $60 \%$ more often than adult females (Table 2; Fig. 2). Potential challengers visited middens with the same frequency as adult females (Table 2; Fig. 2). State also significantly affected the defecation frequency of adults, where territorial males defecated more often than nonterritorial males and females (Table 2; Fig. 3). Finally, nonterritorial males (both subordinate and potential challengers) defecated with the same frequency as females (Table 2; Fig. 3).

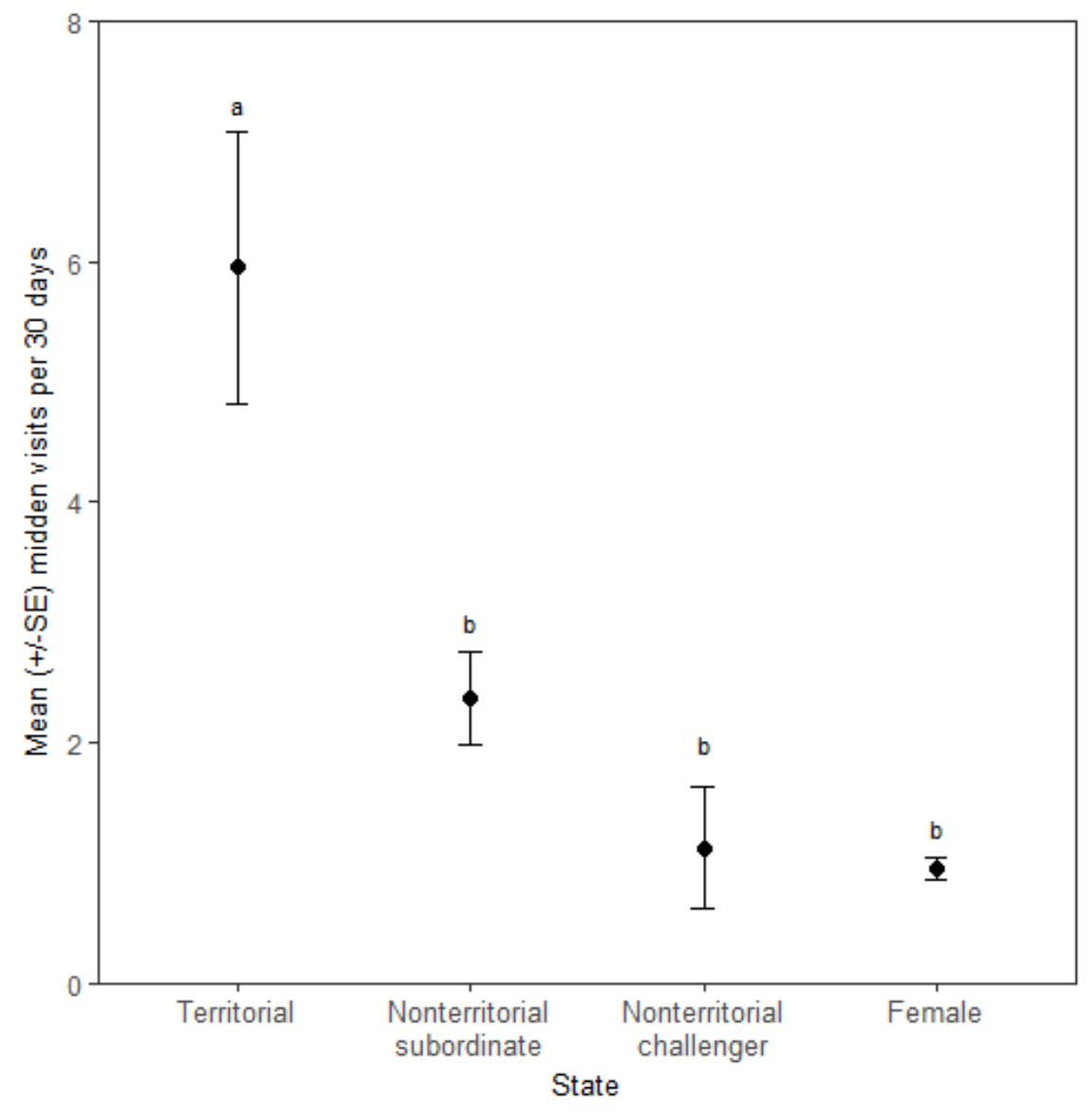

Figure 2. Midden visits by white rhinos of each adult state. Letters indicate significance between groups $(P<0.05)$. 
Table 2. Linear mixed model for visit and defecation frequency of adult white rhinos.

\begin{tabular}{|c|c|c|c|c|c|}
\hline Adult state & Estimate & Std error & $d f$ & $t$-value & $P$-value \\
\hline \multicolumn{6}{|l|}{ Visit frequency } \\
\hline Nonterritorial subordinate*Female & -0.056 & 0.012 & 103 & -4.460 & $<0.001$ \\
\hline Nonterritorial challenger*Female & 0.017 & 0.011 & 103 & 1.529 & 0.424 \\
\hline Territorial*Female & -0.167 & 0.014 & 103 & -11.596 & $<0.001$ \\
\hline Nonterritorial challenger* nonterritorial & 0.072 & 0.015 & 103 & 4.726 & $<0.001$ \\
\hline \multicolumn{6}{|l|}{ subordinate } \\
\hline Territorial* nonterritorial subordinate & -0.111 & 0.018 & 103 & -6.189 & $<0.001$ \\
\hline Territorial* nonterritorial challenger & -0.183 & 0.017 & 103 & -10.854 & $<0.001$ \\
\hline \multicolumn{6}{|l|}{ Defecation frequency } \\
\hline Nonterritorial subordinate*Female & -10.253 & 6.366 & 103 & -1.611 & 0.377 \\
\hline Nonterritorial challenger*Female & 2.184 & 5.580 & 103 & 0.391 & 0.980 \\
\hline Territorial*Female & -89.616 & 7.330 & 103 & -12.226 & $<0.001$ \\
\hline Nonterritorial challenger* nonterritorial & 12.436 & 7.813 & 103 & 1.592 & 0.388 \\
\hline \multicolumn{6}{|l|}{ subordinate } \\
\hline Territorial* nonterritorial subordinate & -79.364 & 9.146 & 103 & -8.678 & $<0.001$ \\
\hline Territorial* nonterritorial challenger & -91.800 & 8.617 & 103 & -10.653 & $<0.001$ \\
\hline
\end{tabular}




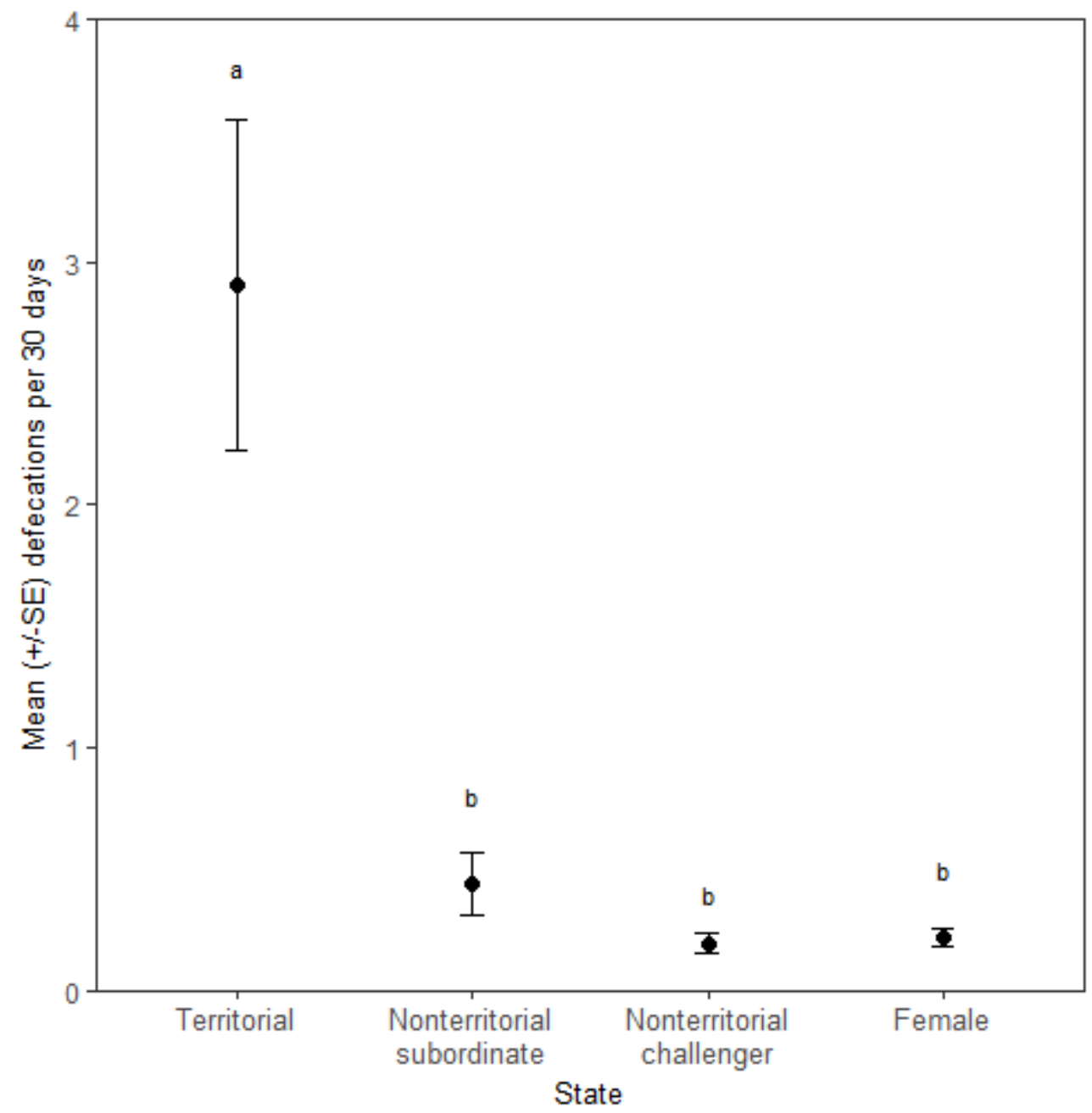

Figure 3. Midden defecations by white rhinos of each adult state. Letters indicate significance between groups $(P<0.05)$

\section{Information acquisition}

State affected information acquisition, where territorial males investigated more often than subordinate males and females, but with the same proportion as potential challengers (Table 3; Fig. 4). However, there was no difference in the investigation of potential challengers and subordinate males. Additionally, females investigated less often than potential challengers but with the same frequently as subordinate males (Table 3; Fig. 4). There was no difference in the sex of the dung sniffed by adults, with male and female dung sniffed equally by males and females (Table 4; Fig. 5a). Further, all adults, regardless of state, investigated the same dung piles (Table 5; Fig. 5b), where territorial male dung was sniffed most often. 
Table 3. Generalised linear mixed model for information acquisition of adult white rhinos.

\begin{tabular}{lcccc}
\hline Adult state & Estimate & Std error & $Z$-value & $P$-value \\
\hline Nonterritorial subordinate*Female & 0.552 & 0.226 & 2.444 & 0.066 \\
Nonterritorial challenger*Female & $\mathbf{1 . 3 1 2}$ & $\mathbf{0 . 3 3 9}$ & $\mathbf{3 . 8 7 1}$ & $<\mathbf{0 . 0 0 1}$ \\
Territorial*Female & $\mathbf{1 . 3 7 7}$ & $\mathbf{0 . 2 5 1}$ & $\mathbf{5 . 4 8 3}$ & $\mathbf{0 . 0 0 1}$ \\
Nonterr challenger* nonterr subordinate & 0.760 & 0.370 & 2.054 & 0.161 \\
Territorial* nonterritorial subordinate & $\mathbf{0 . 8 2 6}$ & $\mathbf{0 . 2 9 2}$ & $\mathbf{2 . 8 3 1}$ & $\mathbf{0 . 0 2 3}$ \\
Territorial* nonterritorial challenger & 0.066 & 0.385 & 0.170 & 0.998 \\
\end{tabular}

Bold indicates factors significant at $P<0.05$.

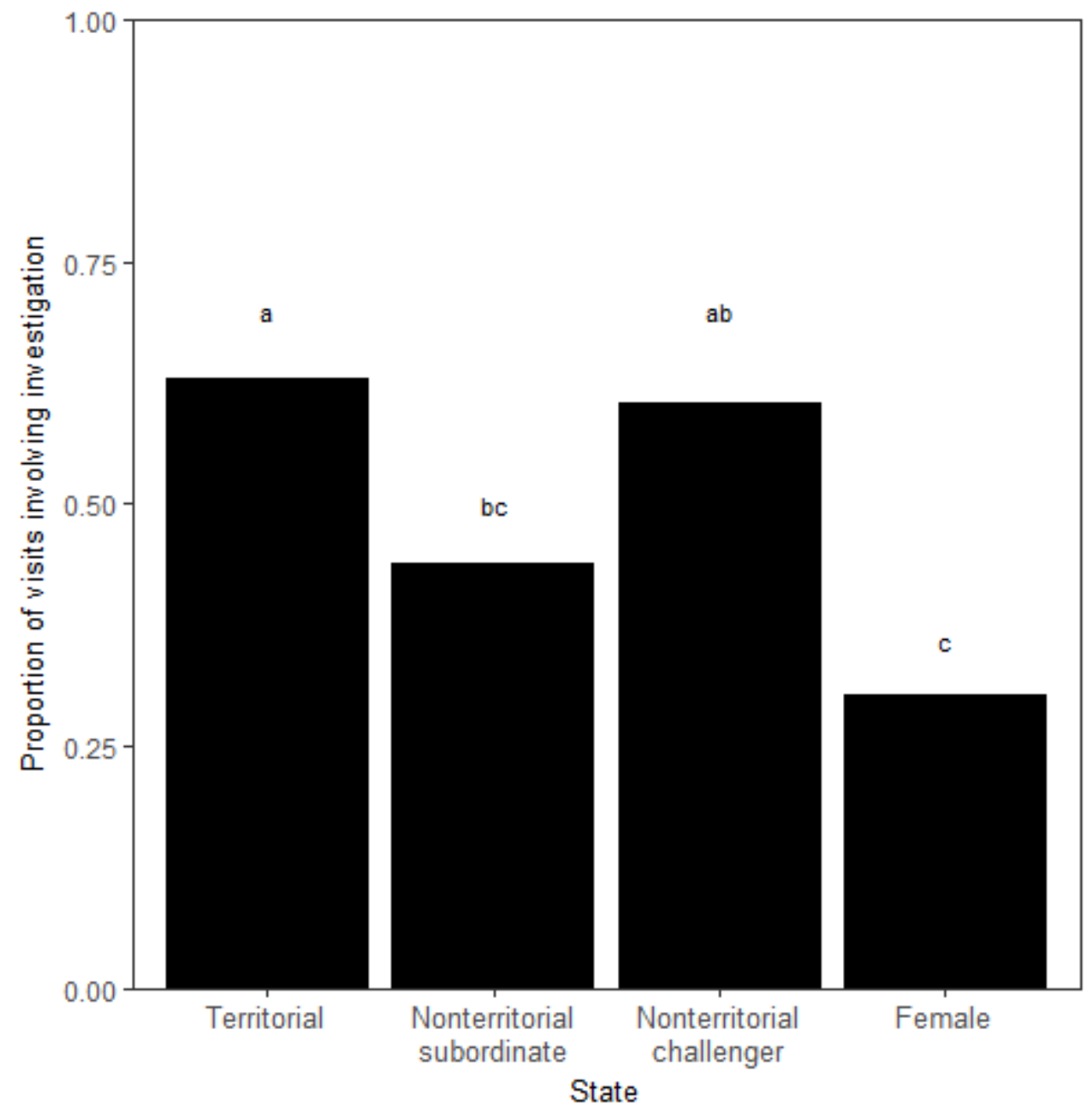

Figure 4. Proportion of midden visits involving investigation by white rhinos of each adult state. Letters indicate significance between groups $(P<0.05)$. 
Table 4. Generalised linear mixed model for the investigation of male and female dung.

\begin{tabular}{lcccc}
\hline State of investigating rhino & Estimate & Std error & $Z$-value & $P$-value \\
\hline Nonterritorial subordinate*Female & -0.418 & 0.337 & -1.241 & 0.594 \\
Nonterritorial challenger*Female & 0.305 & 0.481 & 0.634 & 0.919 \\
Territorial*Female & 0.108 & 0.383 & 0.281 & 0.992 \\
Nonterr challenger* nonterr subordinate & 0.723 & 0.503 & 1.437 & 0.469 \\
Territorial* nonterritorial subordinate & 0.526 & 0.409 & 1.286 & 0.565 \\
Territorial* nonterritorial challenger & -0.197 & 0.536 & -0.368 & 0.982 \\
\hline
\end{tabular}

Bold indicates factors significant at $P<0.05$.
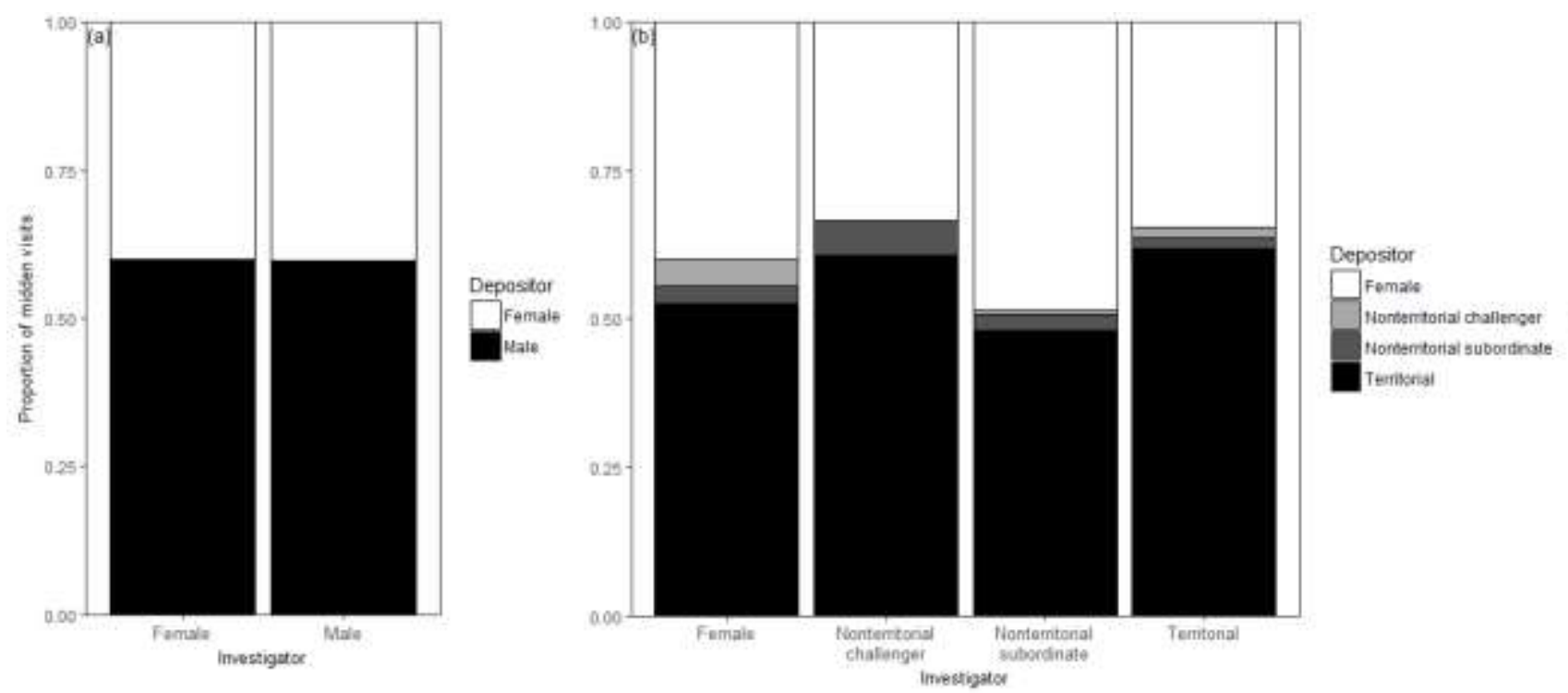

Figure 5. Dung piles identified by (a) sex, and (b) adult state that were investigated by adults. Letters indicate significance between groups $(P<0.05)$.

Table 5. Generalised linear mixed model for the investigation of adult dung of each state.

\begin{tabular}{llccc}
\hline State of investigating rhino & Estimate & Std error & $Z$-value & $P$-value \\
\hline Nonterritorial subordinate*Female & 0.134 & 1.028 & 0.131 & 0.999 \\
Nonterritorial challenger*Female & -0.727 & 1.157 & -0.628 & 0.922 \\
Territorial*Female & 0.385 & 1.212 & 0.317 & 0.989 \\
Nonterr challenger* nonterr subordinate & -0.861 & 1.266 & -0.680 & 0.903 \\
Territorial* nonterritorial subordinate & 0.250 & 1.315 & 0.190 & 0.998 \\
Territorial* nonterritorial challenger & 1.111 & 1.419 & 0.783 & 0.860 \\
\hline
\end{tabular}

Bold indicates factors significant at $P<0.05$. 
Table 6. $X^{2}$ results of dung investigation.

\begin{tabular}{|c|c|c|c|}
\hline Adult state & $d f$ & $X^{2}$ & $P$-value \\
\hline \multicolumn{4}{|l|}{ Territorial males } \\
\hline Territorial* nonterritorial challenger & 3 & 166.420 & $<0.001$ \\
\hline Territorial* nonterritorial subordinate & 3 & 166.420 & $<0.001$ \\
\hline Territorial*Female & 3 & 166.420 & $<0.001$ \\
\hline Nonterr challenger* nonterr subordinate & 3 & 166.420 & 1.000 \\
\hline Nonterritorial challenger*Female & 3 & 166.420 & $<0.001$ \\
\hline Nonterritorial subordinate*Female & 3 & 166.420 & $<0.001$ \\
\hline \multicolumn{4}{|l|}{ Nonterritorial subordinate males } \\
\hline Territorial* nonterritorial challenger & 3 & 128.810 & $<0.001$ \\
\hline Territorial* nonterritorial subordinate & 3 & 128.810 & $<0.001$ \\
\hline Territorial*Female & 3 & 128.810 & 0.933 \\
\hline Nonterr challenger* nonterr subordinate & 3 & 128.810 & 0.216 \\
\hline Nonterritorial challenger*Female & 3 & 128.810 & $<0.001$ \\
\hline Nonterritorial subordinate*Female & 3 & 128.810 & $<0.001$ \\
\hline \multicolumn{4}{|l|}{ Nonterritorial potential challenger males } \\
\hline Territorial* nonterritorial challenger & 3 & 30.636 & $<0.001$ \\
\hline Territorial* nonterritorial subordinate & 3 & 30.636 & $<0.001$ \\
\hline Territorial*Female & 3 & 30.636 & 0.127 \\
\hline Nonterr challenger* nonterr subordinate & 3 & 30.636 & 0.157 \\
\hline Nonterritorial challenger*Female & 3 & 30.636 & 0.002 \\
\hline Nonterritorial subordinate*Female & 3 & 30.636 & 0.019 \\
\hline \multicolumn{4}{|l|}{ Females } \\
\hline Territorial* nonterritorial challenger & 3 & 102.300 & $<0.001$ \\
\hline Territorial* nonterritorial subordinate & 3 & 102.300 & $<0.001$ \\
\hline Territorial*Female & 3 & 102.300 & 0.154 \\
\hline Nonterr challenger* nonterr subordinate & 3 & 102.300 & 0.527 \\
\hline Nonterritorial challenger*Female & 3 & 102.300 & $<0.001$ \\
\hline Nonterritorial subordinate*Female & 3 & 102.300 & $<0.001$ \\
\hline
\end{tabular}

Bold indicates factors significant at $P<0.05$. 
The level of investigation of dung by adult white rhinos varied with state. Territorial males; territorial male $>$ female $>$ nonterritorial challenger $=$ nonterritorial subordinate $($ Table $6 ;$ Fig. $5 b)$. Nonterritorial subordinates; territorial male $=$ female $>$ nonterritorial subordinate $=$ nonterritorial challenger (Table 6; Fig. 5b). Nonterritorial challengers; territorial male $=$ female $>$ nonterritorial subordinate $=$ nonterritorial challenger $($ Table 6 ; Fig. $5 b)$. Females; territorial males $=$ females $>$ nonterritorial subordinate $=$ nonterritorial challenger $($ Table $6 ;$ Fig. $5 b)$.

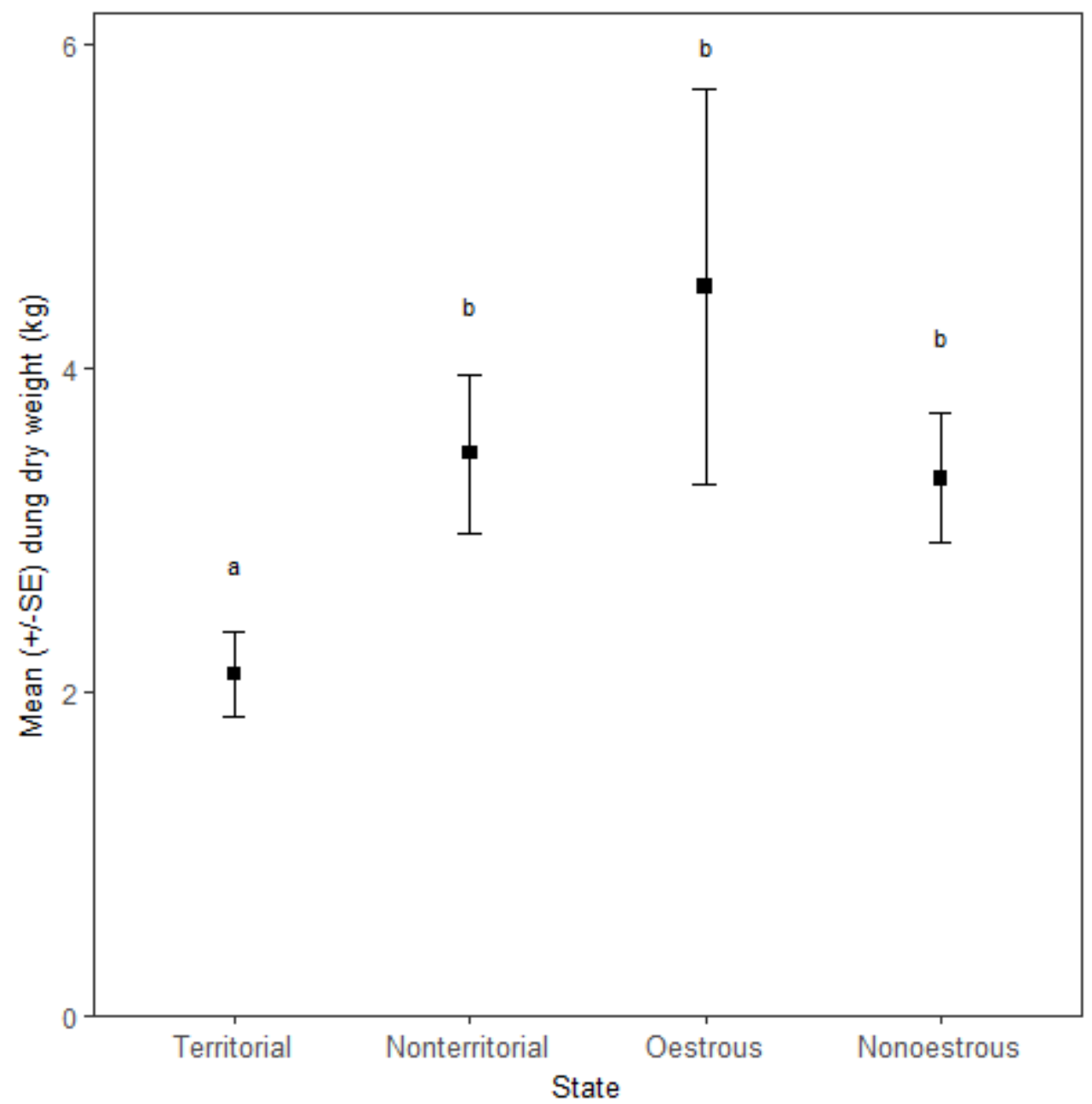

Figure 6. Mean dung dry weight from adult white rhinos of each adult state. Letters indicate significance between groups $(P<0.05)$.

\section{Dung weight}

Dung piles from territorial males were significantly lighter than dung piles from nonterritorial males $\left(\mathrm{H}_{3}=5.804, P=0.027\right.$; Fig. 6), oestrous females $\left(\mathrm{H}_{3}=5.804, P=0.028\right.$; Fig. 6), and nonoestrous females 
$\left(\mathrm{H}_{3}=5.804, P=0.047\right.$; Fig. 6). The dung piles from nonterritorial males, oestrous females, and nonoestrous females, however, were similar (nonterritorial vs oestrous $\mathrm{H}_{3}=5.804, P=0.319$; nonterritorial vs non-oestrous $\mathrm{H}_{3}=5.804, P=0.345$; oestrous vs nonoestrous $\mathrm{H}_{3}=5.804, P=0.217$; Fig. $6)$.

\section{Defecation location}

Territorial and subordinate males primarily defecated in the centre of the midden (100\% and 65\%, respectively; Table 7, Fig. 7), whereas females and potential challenging males primarily defecated towards the edge or outside of the midden (females: $52 \%$ edge, $22 \%$ outside; potential challenging males: $63 \%$ edge, $6 \%$ outside; Table 7, Fig. 7). However, there was no statistical difference between subordinate and potential challenging males (Table 7; Fig. 7).

Table 7. Linear mixed model for defecation location by adult white rhinos of each state.

\begin{tabular}{llllll}
\hline Adult state & Estimate & Std error & $d f$ & $t$-value & $P$-value \\
\hline Nonterritorial subordinate*Female & $\mathbf{1 . 1 1 9}$ & $\mathbf{0 . 2 3 5}$ & $\mathbf{7 2}$ & $\mathbf{4 . 7 7 2}$ & $<\mathbf{0 . 0 0 1}$ \\
Nonterritorial challenger*Female & 0.521 & 0.276 & 72 & 1.889 & 0.242 \\
Territorial*Female & $\mathbf{1 . 8 5 0}$ & $\mathbf{0 . 2 5 5}$ & $\mathbf{7 2}$ & $\mathbf{7 . 2 5 9}$ & $<\mathbf{0 . 0 0 1}$ \\
Nonterr challenger* nonterr subordinate & -0.599 & 0.325 & 72 & -1.841 & 0.263 \\
Territorial* nonterritorial subordinate & 0.730 & 0.308 & 72 & 2.371 & 0.092 \\
Territorial* nonterritorial challenger & $\mathbf{1 . 3 2 9}$ & $\mathbf{0 . 3 4 0}$ & $\mathbf{7 2}$ & $\mathbf{3 . 9 0 7}$ & $\mathbf{0 . 0 0 1}$ \\
\hline
\end{tabular}

Bold indicates factors significant at $P<0.05$. 


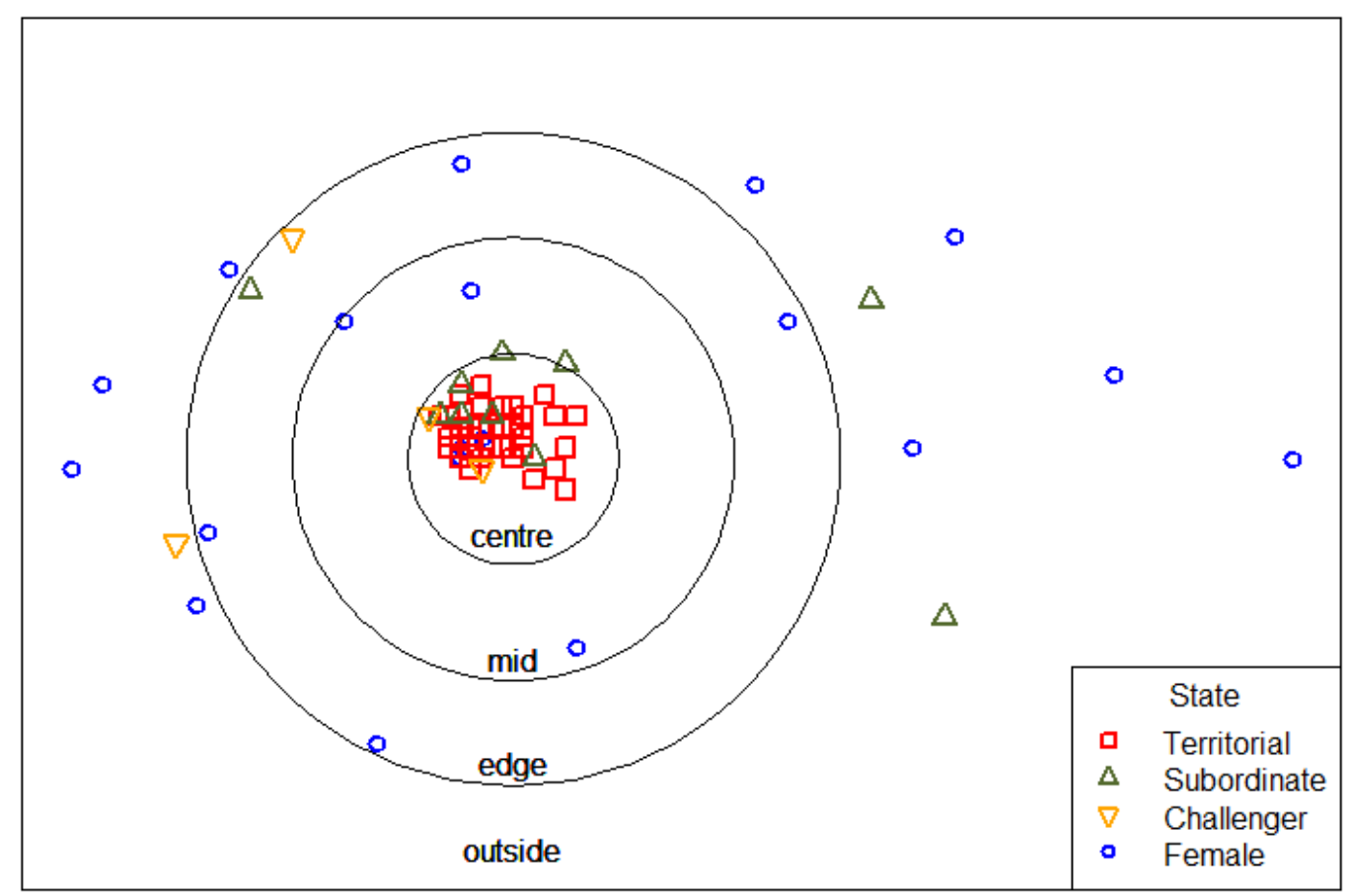

Figure 7. Example of defecation location by each adult white rhino class within a focal midden.

\section{Discussion}

Olfactory communication could be one of the least reliable forms of communication, as the direction and duration of information transfer, and thus the probability of being detected by a desired target, is greatly influenced by wind, heat, and other factors (Alberts, 1992; Bossert, 1968; Nimmermark \& Gustafsson, 2005). However, some mammals increase the detection of their olfactory signals by utilising communal marking sites (Darden et al., 2008; Eppley et al., 2016; Rodgers et al., 2015). White rhinos defecate in communal middens, but it is unclear why or how frequently individuals use these sites. As information on sex, age, territorial and oestrous state are identifiable via dung odours (Marneweck et al., 2017a), it is likely that middens act as information centres for white rhinos. Upon exploring this, we found that, of the different adult states, territorial males visited and utilised middens most of all. Moreover, these males focused their olfactory investigation primarily on their own dung, followed by those from adult females, and lastly, nonterritorial males. We found a similar pattern of olfactory investigation for nonterritorial males and females. Within middens, we found that there was a spatial order to where the rhinos defecated. Specially, territorial males defecated 
exclusively in the centre, subordinate males defecated both within the centre and around the periphery, while potential challengers and females defecated primarily around the midden periphery.

\section{Visit and defecation frequency}

The extensive visit and use of middens by territorial males suggests that middens are important sources of information for these individuals. This is in line with a polygynous mating system, where males deposit information for territorial defence and acquire information on female reproductive state (Emlen \& Oring, 1977). As territorial males defecate in middens along territory boundaries, and throughout the territory, it is likely that they use olfactory cues to indicate territory ownership (OwenSmith, 1975). This can be directed at rival males (i.e. male-male communication), and/or towards adult females (potential mates) visiting the territory (i.e. male-female communication). Midden use by meerkats is also dominated by reproductive males (Jordan, 2007), where all individuals visit middens but males deposit scent marks more often. Additionally, territorial male oribi also mark with dung at a higher frequency than females and males without a harem (Brachares \& Arcese, 1999). Moreover, the high frequency of visits to the middens, coupled with greater investigation (i.e. sniffing), suggests that territorial males are the individuals that are acquiring the most information. This would be important for territorial defence (e.g. detecting an intruding rival male), and for increasing their fitness (e.g. locating a visiting oestrous female).

\section{Information acquisition}

Interestingly, all the territorial males extensively sniffed their own dung when visiting middens. This was unexpected, but it is possible that they did this to assess the strength of their own olfactory signals within the midden. As territorial males deposit small volumes of dung within middens, and spread it by kicking, the greater surface area likely reduces odour persistence (Marneweck, Jürgens, \& Shrader, 2017b). Thus, as these odours likely signal territorial ownership, it would be important for males to ensure that their dung odours are detectable. Group-living European badgers (Meles meles) mark territory boundaries with faeces (Kilshaw, Newman, Buesching, Bunyan, \& Macdonald, 2009). During visits to these middens, badgers spend time investigating their own faecal marks, as well as those from alien groups (Palphramand \& White, 2007). Moreover, Palphramand and White (2007) 
noted that re-marking was rare in their study. Perhaps, like white rhinos, individuals were sniffing their own faeces to assess signal strength, and if still active, were restraining from re-marking in the midden.

Similar to territorial males, we found that all other adults (subordinate males, potential challenging males, and females) displayed a similar pattern of olfactory exploration by focusing their sniffing on territorial male and adult female dung. Sniffing the territorial male's dung would allow these individuals to determine territory ownership, and how recently the territorial male was in the area. Moreover, for potential challengers, sniffing the dung of the territorial male may provide insight into his body condition (Gosling \& Roberts, 2001; Rajagopal, Archunan, Geraldine, \& Balasundaram, 2010), and thus help assess whether he can be challenged for territory ownership. With regard to the sniffing of adult female dung, territorial males tend to monopolise mating opportunities within their territories (Owen-Smith, 1973). However, nonterritorial males can obtain sneaky copulations (Guerier et al., 2012). Thus, it makes sense that both subordinate males and potential challengers would be interested in the reproductive state of females in the area. In addition, potential challengers may get an idea of the number of females that move through the territorial male's territory, and thus gain insight into territory quality (i.e. number of potential mates). In separating nonterritorial males into subordinate residents and potential challengers, it is possible that we may have misclassified some individuals. However, as we were able to record a large sample of visits by these different males $(N=$ 282) over the average 222 days that the cameras were operational, we are confident that the number of potential misclassifications are very small, and thus unlikely to affect our results.

For females, defecating in middens is a way to advertise oestrous state (i.e. female-male communication). However, females did not just deposit information, but also obtained information when visiting middens. They investigated the territorial male's dung and, less frequently, the dung from nonterritorial males. However, this may be due to nonterritorial male dung not always being present in the middens. By investigating the territorial male's dung, a female may be able to assess his quality (Charpentier, Boulet, \& Drea, 2008; Johansson \& Jones, 2007). This would then help her to decide whether to breed with him or not. As nonterritorial males sometimes breed (Guerier et al., 2012), it is possible that females may be assessing the quality of all the males that have defecated in 
the midden, and thus not limiting their options to breeding with the territory owners. Furthermore, it may be possible that oestrous females may use middens to assess male quality, and hence avoid territories of sub-optimal males when in oestrus (White et al., 2007). However, as the oestrous state of females in this study was unknown, this would require further investigation.

In addition to investigating the dung of adult males, females surprisingly also sniffed the dung of other adult females. In fact, they did this almost as often as they explored the dung of territorial males, suggesting female-female communication. The question is, however, what are they communicating and/or what information are they interested in obtaining? Adult females live in home ranges that extensively overlap with those of other females (Owen-Smith, 1973, 1975; Rachlow et al., 1999; White et al., 2007). Thus, it is highly unlikely that females use olfactory signals to demarcate home range boundaries. Moreover, as male white rhinos do not provide any parental care (OwenSmith, 1973), females are unlikely to compete over mates. Jordan et al. (2011) highlight that scentmarking in females is often over-looked and is poorly understood. Female intra-sexual over-marking in banded mongooses (Mungos mungo) was not a result of food competition, reproductive suppression, or mate competition (Jordan et al., 2011). We suggest that intra-sexual investigation of dung in female white rhinos is a function of familiarity, keeping track of the other females whose home ranges overlap, and thus know who is close by. A by-product of this, is that the presence of dung from a range of females within middens may transmit information on the local density of adult females, which dispersing individuals may use to determine where to settle (Shrader \& Owen-Smith, 2002). Moreover, females may use information on the number of females moving through the territory as an indicator of territorial male quality (White et al., 2007).

\section{Defecation location}

One factor that may increase signal detection and thus enhance detectability is the spatial arrangement of dung within middens. The location of a scent mark is important in several species. For example, giant pandas (Ailuropoda melanoleuca) spend more time investigating odours placed higher from the ground because that indicates body size and associated competitive ability (White, Swaisgood, \& Zhang, 2002). In addition, female dwarf mongooses (Helogale parvula) spend more time 
investigating scent marks placed higher from the ground, even when they did not differ chemically (Sharpe, 2015). This suggests that the location of a scent mark is as important as the odour profile itself.

For white rhinos, many different individuals defecate in one midden (up to 16 individuals in this study (Appendix 1)). By defecating in specific areas, white rhinos add a spatial component to their olfactory signals, which may increase detectability and strengthen information on identity (Sharpe, 2015; White et al., 2002). By defecating extensively in the centre of middens, both territorial and subordinate males may indicate residency. Whereas the kicking of dung in the centre of the midden may indicate territory ownership. Potential challenging males defecated primarily around the edge of the midden, possibly to indicate to the territorial male that they were there, indicating subordinance (Owen-Smith, 1973) and thus avoiding confrontation with the territory owner. In contrast, it is possible that when these males defecated in the centre of the middens, they were issuing a challenge to the territorial male. Although we were unable to record any direct confrontations between individuals, we often observed that a territorial male would kick aggressively and over-mark if he found a potential challenger's dung in the centre of the midden (as opposed to a subordinate male's dung). Further, the territorial male often returned the same day (up to three times) to investigate the midden with no further defecation. However, data were insufficient to draw any conclusions, and this requires further exploration. Finally, the peripheral defecations of adult females likely increases the detectability of female dung piles.

\section{Dung weight}

Within adults, territorial males defecated more frequently in middens, likely to reaffirm territory ownership. As they have a number of middens both along boundaries and within their territory, it makes sense for these males to reduce the volume of dung per deposit and increase the frequency of defecation. By limiting dung volume per defecation event, this allows them to regulate their dung output, a strategy also utilised by several other communally defecating, territorial ungulates (e.g. oribi (Brachares \& Arcese, 1999), common duikers Sylvicapra grimmia (Lunt \& Mhlanga, 2011), Chinese water deer Hydropotes inermis (Sun, Xiao, \& Dai, 1994)). Ultimately, dung is a limited resource, 
therefore territorial males utilising dung for olfactory communication across their territory must manage their dung output to ensure effective distribution. Due to the nature of territorial dung kicking, it is possible that part of the territorial males' defecation was not collected. This would mean that the weight of territorial male defecations was underestimated. However, due to the immediate collection of dung ( $<5$ minutes), and the ease of identifying fresh dung due to heat and colour, it is unlikely that large portions of dung were not collected and thus affect the results. Additionally, it is possible that the dung output of white rhinos could vary throughout the day, and thus spatially across the middens. However, we collected dung throughout the day (range= 06:10-18:00). Thus, if there were temporal and spatial variation in dung weight we would have expected a wide variance in the dung weights we recorded from the different white rhino states, which we did not. As a result, we are confident that our data provide a reliable measure of white rhino dung weight.

The results of our study suggest that middens are in fact information centres for white rhinos. Territorial males seem to be the main users, with them likely transferring information on territorial ownership (male-male and male-female communication), and receiving information from visiting adult females (female-male communication) and nonterritorial males (male-male communication). Yet, as both nonterritorial males and adult females deposit and obtain information from middens as well, it is likely that middens are also key information sources for these individuals. Overall, our results indicate that middens are key components of white rhino communication. Yet, as a number of mammals defecate in communal middens (Dröscher \& Kappeler, 2014; Jordan et al., 2007), the role of middens as a source of information transfer is likely not restricted to white rhinos alone.

\section{References}

Alberts, A. C. (1992). Constraints on the design of chemical communication systems in terrestrial vertebrates. The American Naturalist, 139, S62-S89.

Archunan, G., \& Rajagopal, T. (2013). Detection of estrus in Indian blackbuck: Behavioural, hormonal and urinary volatiles evaluation. General and Comparitive Endocrinology, 181, 156-166. 
Barja, I., de Miguel, F. J., \& Bárcena, F. (2005). Faecal marking behaviour of Iberian wolf in different zones of their territory. Folia Zoologica, 54, 21-29.

Bates, D., Maechler, M., Bolker, B., \& Walker, S. (2015). Fitting linear mixed-effects models using lme4. Journal of Statistical Software, 67, 1-48.

Bossert, W. H. (1968). Temporal patterning in olfactory communication. Journal of Theoretical Biology, 18, 157-170.

Brachares, J. S., \& Arcese, P. (1999). Scent marking in a territorial African antelope: II. The economics of marking with faeces. Animal Behaviour, 57, 11-17.

Brotherton, P. N. M., \& Manser, M. B. (1997). Female dispersion and the evolution of monogamy in the dik-dik. Animal Behaviour, 54, 1413-1424.

Charpentier, M. J., Boulet, M., \& Drea, C. M. (2008). Smelling right: the scent of male lemurs advertises genetic quality and relatedness. Molecular Ecology, 17, 3225-3233.

Cross, H. B., Zedrosser, A., Nevin, O., \& Rosell, F. (2014). Sex discrimination via anal gland secretion in a territorial monogamous mammal. Ethology, 120, 1044-1052.

Darden, S. K., Steffensen, L. K., \& Dabelsteen, T. (2008). Information transfer among widely spaced individuals: latrines as a basis for communication networks in the swift fox? Animal Behaviour, 75, 425-432.

Dröscher, I., \& Kappeler, P. M. (2014). Maintenance of familiarity and social bonding via communal latrine use in a solitary primate (Lepilemur leucopus). Behavioral Ecology and Sociobiology, 68, 2043-2058.

Dunbar, R. I. M., \& Dunbar, E. P. (1974). Social organization and ecology of the klipspringer (Oreotragus oreotragus) in Ethiopia. Zeitschrift für Tierpsychologie, 35, 481-493.

Dunham, M. L., Warner, R. R., \& Lawson, J. W. (1995). The dynamics of territory acquistion: a model of two coexisting strategies. Theoretical Population Biology, 47, 347-364.

Emlen, S. T., \& Oring, L. W. (1977). Ecology, sexual selection, and the evolution of mating systems. Science, 197, 215-223. 
Eppley, T. M., Ganzhorn, J. U., \& Donati, G. (2016). Latrine behaviour as a multimodal communicatory signal station in wild lemurs: the case of Hapalemur meridionalis. Animal Behaviour, 111, 57-67.

Gosling, L. M., \& Roberts, S. C. (2001). Scent-marking by male mammals: cheat-proof signals to competitors and mates. Advances in the Study of Behavior, 30, 169-217.

Guerier, A. S., Bishop, J. M., Crawford, S. J., Schmidt-Kuntzel, A., \& Stratford, K. J. (2012). Parentage analysis in a managed free ranging population of southern white rhinoceros: genetic diversity, pedigrees and management. Conservation Genetics, 13, 811-822.

Hendrichs, H., \& Hendrichs, U. (1971). Dikdik und elefanten: R. Piper.

Hillman-Smith, A. K. K., Owen-Smith, N., Anderson, J. L., Hall-Martin, A. J., \& Selaladi, J. P. (1986). Age estimation of the white rhinoceros (Ceratotherium simum). Journal of Zoology, $210,355-379$.

Johansson, B. G., \& Jones, T. M. (2007). The role of chemical communication in mate choice. Biological Reviews of the Cambridge Philosophical Society, 82, 265-289.

Jordan, N. R. (2007). Scent-marking investment is determined by sex and breeding status in meerkats. Animal Behaviour, 74, 531-540.

Jordan, N. R., Cherry, M. I., \& Manser, M. B. (2007). Latrine distribution and patterns of use by wild meerkats: implications for territory and mate defence. Animal Behaviour, 73, 613-622.

Jordan, N. R., Mwanguhya, F., Kyabulima, S., Rüedi, P., Hodge, S. J., \& Cant, M. A. (2011). Scent marking in wild banded mongooses: 3. Intrasexual overmarking in females. Animal Behaviour, 81, 51-60.

Karthikeyan, K., Muniasamy, S., SankarGanesh, D., Achiraman, S., \& Archunan, G. (2013). Faecal chemical cues in water buffalo that facilitate estrus detection. Animal Reproduction Science, 138, 163-167.

Kilshaw, K., Newman, C., Buesching, C., Bunyan, J., \& Macdonald, D. (2009). Coordinated latrine use by European badgers, Meles meles: potential consequences for territory defense. Journal of Mammalogy, 90, 1188-1198. 
Kimura, R. (2001). Volatile substances in feces, urine and urine-marked feces of feral horses. Canadian Journal of Animal Science, 81, 411-420.

Kretzschmar, P., Ganslosser, U., Goldschmid, A., \& Aberham, A. (2001). Stimulation of territorial and mating behaviour by faecal samples. A comparative study on behaviour of captive and free-living white rhinoceros. Paper presented at the International Elephant and Rhino Research Symposium, Vienna, Austria.

Laurie, A. (1982). Behavioural ecology of the Greater one-horned rhinoceros (Rhinoceros unicornis). Journal of Zoology London, 196, 307-341.

Lunt, N., \& Mhlanga, M. R. (2011). Defecation rate variability in the common duiker: importance of food quality, season, sex and age. South African Journal of Wildlife Research, 41, 29-35.

Marneweck, C., Jürgens, A., \& Shrader, A. M. (2017a). Dung odours signal sex, age, territorial and oestrous state in white rhinos. Proceedings of the Royal Society B: Biological Sciences, 284, 20162376.

Marneweck, C., Jürgens, A., \& Shrader, A. M. (2017b). Temporal variation of white rhino dung odours. Journal of Chemical Ecology, 43, 955-965.

Nimmermark, S., \& Gustafsson, G. (2005). Influence of temperature, humidity and ventilation rate on the release of odor and ammonia in a floor housing system for laying hens. Agricultural Engineering International, 7, 1-14.

Owen-Smith, N. (1971). Territoriality in the white rhinoceros (Ceratotherium simum) Burchell. Nature, 231, 294-296.

Owen-Smith, N. (1973). The behavioural ecology of the white rhinoceros. $\mathrm{PhD}$, The University of Wisconsin, USA.

Owen-Smith, N. (1975). The social ethology of the white rhinoceros Ceratotherium simum (Burchell 1817). Zeitschrift für Tierpsychologie, 38, 337-384.

Owen-Smith, N. (1988). Megaherbivores. The influence of very large body size on ecology. Cambridge, UK: Cambridge University Press.

Palphramand, K. L., \& White, P. C. L. (2007). Badgers, Meles meles, discriminate between neighbour, alien and self scent. Animal Behaviour, 74, 429-436. 
Pienaar, D. J., Bothma, J. d. P., \& Theron, G. K. (1993). White rhinoceros range size in the southwestern Kruger National Park. Journal of Zoology, 229(4), 641-649.

Pinheiro, J., Bates, D., DebRoy, S., Sarkar, D., \& Team, R. C. (2015). nlme: linear and nonlinear mixed effects model. Retrieved from https://cran.r-project.org/web/packages/nlme/index.html

Rachlow, J. L., Kie, J. G., \& Berger, J. (1999). Territoriality and spatial patterns of white rhinoceros in Matobo National Park, Zimbabwe. African Journal of Ecology, 37, 295-304.

Rajagopal, T., Archunan, G., Geraldine, P., \& Balasundaram, C. (2010). Assessment of dominance hierarchy through urine scent marking and its chemical constituents in male blackbuck Antelope cervicapra, a critically endangered species. Behavioural Processes, 85, 58-67.

Roberts, S. C., \& Dunbar, R. I. M. (2000). Female territoriality and the function of scent-marking in a monogamous antelope (Oreotragus oreotragus). Behavioral Ecology and Sociobiology, 47, 417-423.

Rodgers, T. W., Giacalone, J., Heske, E. J., Pawlikowski, N. C., \& Schooley, R. L. (2015). Communal latrines act as potentially important communication centers in ocelots Leopardus pardalis. Mammalian Biology, 80, 380-384.

Schenkel, R., \& Schenkel-Hulliger, L. (1969). Ecology and behaviour of the black rhinoceros (Diceros bicornis L.): a field study (Vol. 5). Hamburg: Verlag Paul Paneg.

Sharpe, L. L. (2015). Handstand scent marking: height matters to dwarf mongooses. Animal Behaviour, 105, 173-179.

Shrader, A. M., \& Owen-Smith, N. (2002). The role of companionship in the dispersal of white rhinoceros (Ceratotherium simum). Behavioral Ecology and Sociobiology, 52, 255-261.

Stoffel, M. A., Caspers, B. A., Forcada, J., Giannakara, A., Baier, M., Eberhart-Phillips, L., . . . Hoffman, J. I. (2015). Chemical fingerprints encode mother-offspring similarity, colony membership, relatedness, and genetic quality in fur seals. Proceedings of the National Academy of Sciences U.S.A., 112, E5005-5012.

Sun, L., Xiao, B., \& Dai, N. (1994). Scent marking behaviour in the male Chinese water deer. Acta Theriologica 39, 177-184. 
Team, R. C. (2016). A language and environment for statistical computing. Vienna: R Foundation for Statistical Computing. Retrieved from https://www.R-project.org/

Vaglio, S., Minicozzi, P., Romoli, R., Boscaro, F., Pieraccini, G., Moneti, G., \& Moggi-Cecchi, J. (2016). Sternal gland scent-marking signals sex, age, rank, and group identity in captive mandrills. Chemical Senses, 41, 177-186.

White, A. M., Swaisgood, R., \& Czekala, N. (2007). Ranging patterns in white rhinoceros, Ceratotherium simum simum: implications for mating strategies. Animal Behaviour, 74, 349356.

White, A. M., Swaisgood, R. R., \& Zhang, H. (2002). The highs and lows of chemical communication in giant pandas (Ailuropoda melanoleuca): effect of scent deposition height on signal discrimination. Behavioral Ecology and Sociobiology, 51, 519-529.

Wronski, T. (2005). Home range overlap and spatial organisation as indicators for territoriality among male bushbuck (Tragelaphus scriptus). Journal of Zoology, 266, 1-9.

Wronski, T., Apio, A., \& Plath, M. (2006). The communicatory significance of localised defecation sites in bushbuck (Tragelaphus scriptus). Behavioral Ecology and Sociobiology, 60, 368-378.

Wronski, T., Apio, A., Plath, M., \& Ziege, M. (2013). Sex differences in the communicatory significance of localized defecation sites in Arabian gazelles (Gazella arabica). Journal of Ethology, 31, 129-140. 


\section{Appendix 1}

Interaction of age and sex

The interaction between age and sex had a significant effect on visit and defecation frequency (Table A1) where, within adults, males visited and defecated more frequently than females (Figs. A1 and A2). Similarly, this interaction significantly affected the proportion of visits involving information acquisition, where adult males investigated more often than adult females (Table A2; Fig. A3). Finally, the interaction between age and sex significantly affected defecation location, where there was no difference between the ages of females, but adult males defecated in different locations to subadults and calves (Table A3; Fig. A4). In all cases, the actions of territorial males are what lead to the significantly higher values for adult males compared to the other age and sex classes.

Table A1. Linear mixed model for visit and defecation frequency of white rhinos.

\begin{tabular}{lcllll}
\hline Factor & Estimate & Std error & $d f$ & $t$-value & $P$-value \\
\hline Visit frequency & & & & & \\
Age & -0.009 & 0.012 & 167 & -0.797 & 0.426 \\
Sex & $\mathbf{0 . 0 5 9}$ & $\mathbf{0 . 0 1 0}$ & $\mathbf{1 6 7}$ & $\mathbf{6 . 0 9 6}$ & $<\mathbf{0 . 0 0 1}$ \\
Age*Sex & $\mathbf{- 0 . 0 4 9}$ & $\mathbf{0 . 0 1 7}$ & $\mathbf{1 6 7}$ & $\mathbf{- 2 . 9 7 3}$ & $\mathbf{0 . 0 0 3}$ \\
Defecation frequency & & & & & \\
Age & -0.005 & 0.006 & 167 & -0.894 & 0.372 \\
Sex & $\mathbf{0 . 0 2 3}$ & $\mathbf{0 . 0 0 5}$ & $\mathbf{1 6 7}$ & $\mathbf{4 . 8 5 0}$ & $<\mathbf{0 . 0 0 1}$ \\
Age*Sex & $\mathbf{- 0 . 0 1 9}$ & $\mathbf{0 . 0 0 8}$ & $\mathbf{1 6 7}$ & $\mathbf{- 2 . 2 9}$ & $\mathbf{0 . 0 2 3}$ \\
\hline
\end{tabular}

Bold indicates factors significant at $P<0.05$. 
Table A2. Generalised linear mixed model for information acquisition by white rhinos.

\begin{tabular}{lcccc}
\hline Factor & Estimate & Std error & $Z$-value & $P$-value \\
\hline Age & $\mathbf{- 1 . 1 0 4}$ & $\mathbf{0 . 3 6 0}$ & $\mathbf{- 3 . 0 6 3}$ & $\mathbf{0 . 0 0 2}$ \\
Sex & $\mathbf{1 . 0 0 2}$ & $\mathbf{0 . 2 0 9}$ & $\mathbf{4 . 8 0 7}$ & $<\mathbf{0 . 0 0 1}$ \\
Age*Sex & $\mathbf{- 1 . 0 5 6}$ & $\mathbf{0 . 4 7 5}$ & $\mathbf{- 2 . 2 2 3}$ & $\mathbf{0 . 0 2 6}$ \\
\hline
\end{tabular}

Bold indicates factors significant at $P<0.05$.

Table A3. Linear mixed model for defecation location by white rhinos.

\begin{tabular}{llllll}
\hline Factor & Estimate & Std error & $d f$ & $t$-value & $P$-value \\
\hline Age & 0.312 & 0.338 & 103 & 0.921 & 0.359 \\
Sex & $\mathbf{- 1 . 1 9 5}$ & $\mathbf{0 . 1 8 5}$ & $\mathbf{1 0 3}$ & $\mathbf{- 6 . 4 6 6}$ & $<\mathbf{0 . 0 0 1}$ \\
Age*Sex & $\mathbf{0 . 9 5 6}$ & $\mathbf{0 . 4 1 9}$ & $\mathbf{1 0 6}$ & $\mathbf{2 . 2 8 1}$ & $\mathbf{0 . 0 2 5}$ \\
\hline
\end{tabular}

Bold indicates factors significant at $P<0.05$.

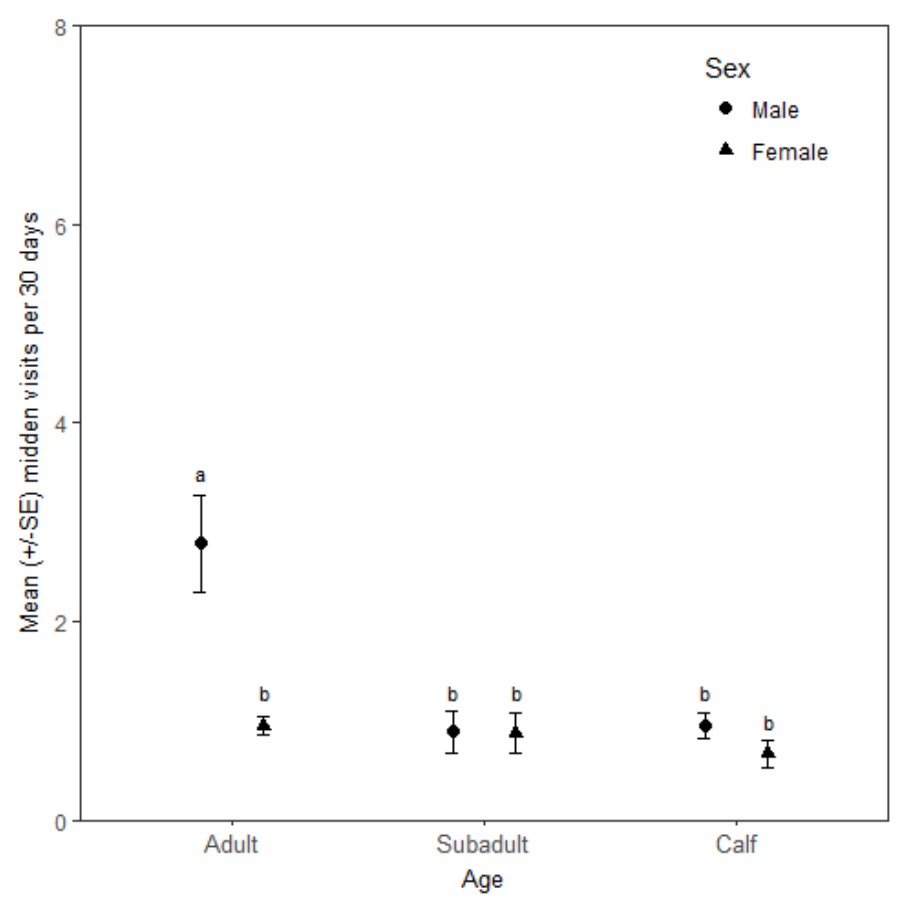

Figure A1. Midden visitation by white rhinos of each age class. Letters indicate significance between groups $(P<0.05)$. 


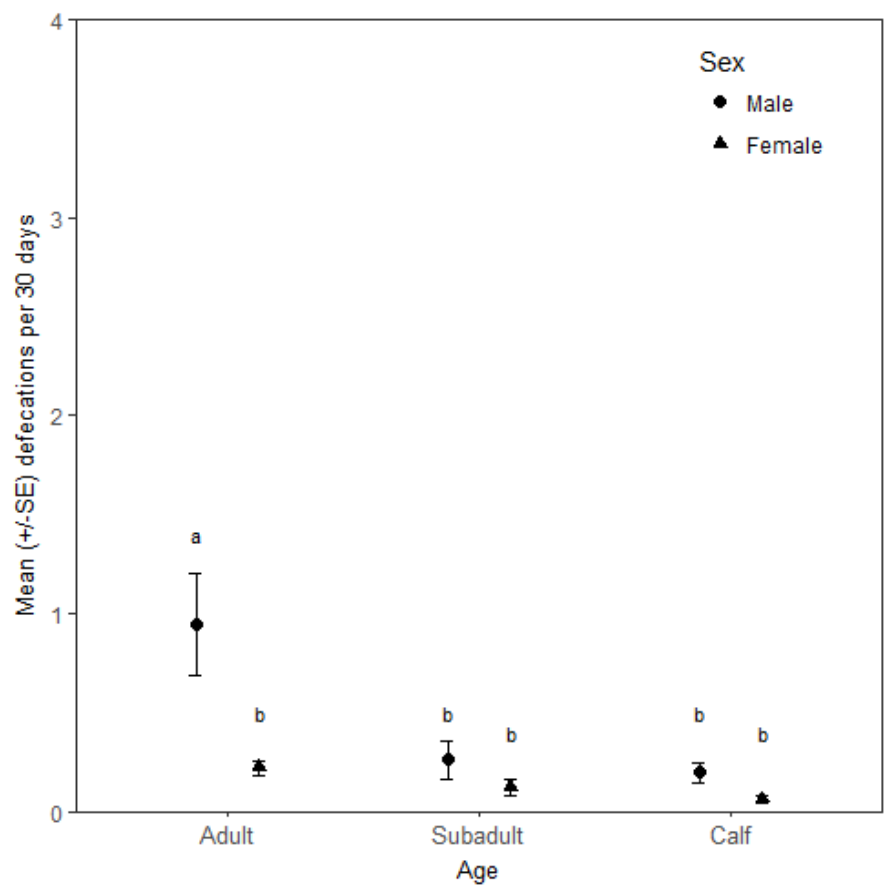

Figure A2. Midden defecations by white rhinos of each age class. Letters indicate significance between groups $(P<0.05)$

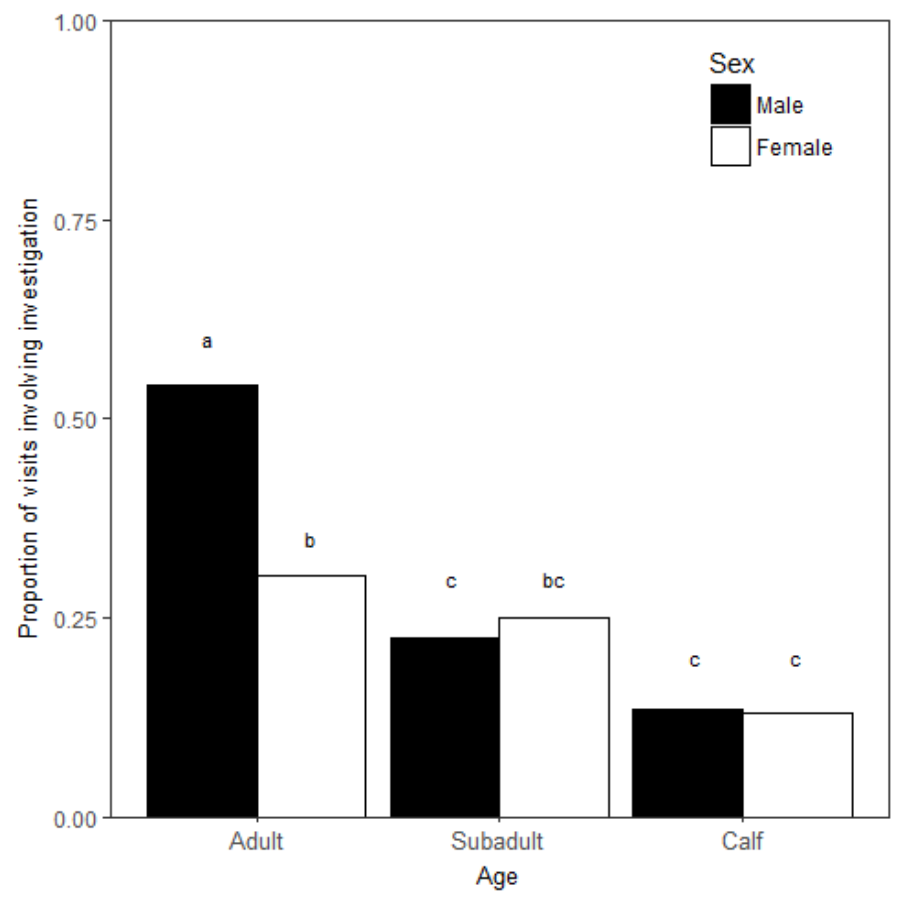

Figure A3. Proportion of midden visits involving investigation by white rhinos of each age class and sex.

Letters indicate significance between groups $(P<0.05)$. 


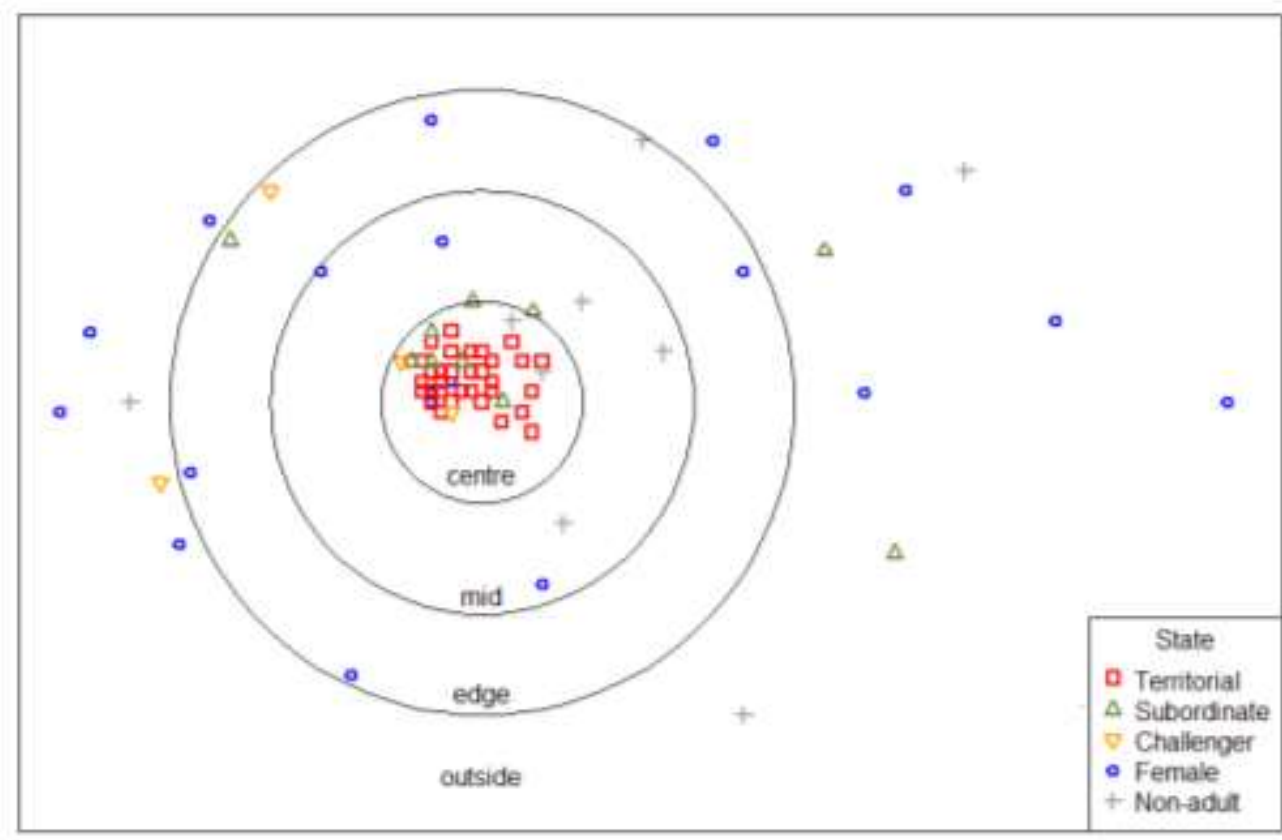

Figure A4. Example of defecation location by each white rhino class within a focal midden 